\title{
CERAMIC TRADITIONS OF MONUMENTS OF THE HARIN TIME IN THE PERM URAL REGION: UNIFORMITY OR DIVERSITY?
}

(C) 2018

\author{
Batueva Nadezhda Sergeevna, specialist of Scientific Department \\ Shmuratko Dmitry Vladimirovich, candidate of historical sciences, dean of History Department \\ Perm State Humanitarian Pedagogical University (Perm, Russian Federation)
}

\begin{abstract}
The results of the technical and technological analysis of ceramics found on the monuments of the Perm Cis-Ural of the era of the Great Migration are presented in the paper. The analysis was carried out in the framework of the historical and cultural approach by AA. Bobrinsky. Five clusters were formed according to the results of multidimensional classification (cluster analysis by the method of k-means) of 67 vessels. Each cluster can be interpreted as an independent pottery tradition. The first tradition is represented by vessels made of without sand clay, taken in a wet state with the addition of a crushed clamshell to the molding mass. This tradition is most widely represented (58,2\% of the vessels of the aggregate sample) and can be associated with the local Glydeen tribes of the early Iron Age. Vessels with organic impurities (manure, organic solution) in the molding mass constitute the second tradition $16,4 \%$ of the vessels of the aggregate sample. The tradition has origins in the Sarmatian world of the Southern Urals and can belong to the tribes who migrated to the region. The third tradition can be traced on vessels made of without sand clay, taken in a wet state with the addition of crushed clamshell and organic solution to the molding mass $19,4 \%$ of the total sample vessels. Tradition illustrates the process of mixing local and foreign populations. The fourth tradition includes a single vessel made of clay with a natural admixture of talc. We can find the origins of the tradition on the eastern slope of the Urals. The fifth tradition is represented by a single vessel made of clay in crushed condition. The fourth and fifth traditions are few; together they make up about $3 \%$ of the vessels of the cumulative sample. The obtained results allow us to speak about the motley cultural palette of Perm Cis-Ural in the era of the Great Migration. The results of the analysis do not agree with the opinion that all ceramics of the early Middle Ages in the Kama Region belong to the one same type and are left by one ethnic group.

Keywords: technical and technological analysis of ceramics; Great migration of peoples; monuments of Harino type; Glyadenovo archaeological culture; Perm Cis-Urals; ethno-cultural processes; migration; cluster analysis; kmeans method; tribal settlement system.
\end{abstract}

УДК 94(47).066

Статья поступила в редакцию 04.01.2018

\section{СЛУЖЕБНАЯ ИЕРАРХИЯ И ТИПОЛОГИЯ ГОРОДОВ И ГОРОДСКИХ ПОСЕЛЕНИЙ, УСТАНОВИВШАЯСЯ НА РУБЕЖЕ ХVIII-XIX ВЕКОВ}

(C) 2018

\author{
Белов Алексей Викторович, кандидат исторических наук, доцент, \\ старший научный сотрудник центра изучения истории территории и населения России \\ Институт российской истории РАН (г. Москва, Российская Федерация)
}

Аннотация. В статье рассматривается один из аспектов кардинального реформирования города, происходившего в правление Екатерины II. Реформа города, проходя в рамках административно-территориальной реформы Екатерины II, была теснейшим образом связана с процессом созданием сети новых «малых» губерний и формированием сети городов и городских поселений в каждом из новых административных образований. Городская сеть (сеть городов и городских поселения) представляла собой комплекс (а не набор) поселений конкретного региона, имеющих (в представлении современников) статус города или его официальные признаки. В процессе бытования внутри нее происходило распределение функций. Набор функций, присущих разным городским поселениям, определяет их характер, облик и лицо в самом широком смысле этого слова. Все функции условно можно поделить на две группы: административные и экономические. В нашем исследовании внимание было обращено на утверждение за городом как части пространственно-поселенческой сети страны набора административных функций. Развитие городской сети в ходе реформ Екатерины II привело к установлению определенных типов городов и городских поселений, с набором черт и обязанностей. При этом между типами поселений установилась твердая иерархия как административных центров. Причина ее появления шире, чем необходимость формального подчинения. Сеть городов и городских поселений страны, установившаяся к первым годам XIX в., по характеру и истории своего происхождения была сложной и весьма неоднотипной конструкцией. В ее состав входили как поселения, официально именовавшиеся словом «город» по правилам своего времени, так и не относящиеся к этой группе. Последние также выполняли городские функции и ставились современниками в один ряд с «официальными» городами, отделяясь от поселений сельских. Наименование поселений городами не всегда соответствовало их хозяйственному качеству. Наряду с основными (административными) типами городов существовали промежуточные формы городских поселений, которые по нормам того времени к городам не относились (безуездные города, заштатные города, посады, местечки). Кроме того, сохранялись архаичные формы поселений, связанные с городами и отчасти исполнявшие их функции. Важным своеобразием данного исторического периода является одновременное существование многочисленных и разнообразных форм городских поселений, в том числе и архаических. Данное обстоятельство вызвано переходным характером времени, проведением адми- 
Белов А.В.

нистративной реформы, а также стремлением власти осуществлять процесс преобразований без кардинального слома и социального протеста.

Ключевые слова: русский город; дореформенный город; дореформенное время; Новое время; средневековый город; реформа города; Екатерина II; губернская реформа; городские поселения; посад; слобода; заштатный город; безуездный город; крепость; урбанизация; городская сеть; городские поселения.

\section{Особенность и характер города}

в контексте исторического периода

Вторая половина XVIII - начало XIX в., бесспорно, порубежный период в истории русского города, который именно в это время обрел ту форму и содержание, в контексте которых он существует и по сей день. Однако еще в первой половине XVIII столетия город трактовался преимущественно в качестве крепости. Именно этот критерий выступал основным при оценке самого понятия город как в официально-государственном, так и в повседневно-бытовом контексте. Важно отметить, что крепостная функция как определяющая характер города предусматривала не только наличие стен и башен, но и организацию жизни поселения: состав жителей, систему управления, внутреннюю структуру и т.д.

К середине XVIII в. нормы средневековой истории себя изживали. Менялся и характер поселенческой системы. Развитие ее структуры требовало отказа от старых представлений и корреляции, исходя из новых условий. Время требовало от государства необходимости разобраться в его городском хозяйстве. Доказательством наличия в это время кризиса представлений о городе и осознания необходимости переустройства и унификации городской системы служат слова, написанные самой Екатериной II в тексте ее «Наказа»: «Нужно иметь одинаковый закон, который бы определил, что есть город» [1, c. 127].

Естественно, что реформы, проводимые государством, преследовали наиболее значимые для него цели. В первую очередь фискально-административные. Однако было бы большой ошибкой полагать, что дальше этого оно не шло. Власти были не менее заинтересованы в решении более широких задач: социальных, правоохранительных, противопожарных и т.д., вызванных переходом от города-крепости к городу - многофункциональному центру. Правда, приоритет всегда оставался за двумя его ведущими функциями: административной и хозяйственной.

В ходе реформы города Екатериной II произошло его переустройство и переосмысление в соответствии с нормами Нового времени. Как в плане населения (от служилых людей и слобожан к «городовым обывателям»), так и в отношении структуры и функций. Причем последние как единый комплекс изучены менее всего.

Небольшой период протекания екатерининской реформы города, естественно, не мог переделать город в корне как явление. Кроме того, страна находилась на стыке эпох. В итоге одновременно существовали черты (в том числе и в виде типов поселений) как Нового времени, так и уходящего Средневековья. Помимо этого на пространной территории России наличествовали формы, унаследованные от разных традиций [2]: территориальных, национальных и иных, объединенных в рамках одной империи. Так, например, были частновладельческие города [3]; го- рода, находившиеся в личной собственность императрицы [4]; местечки [5] и т.д.

К концу столетия не произошел полный отказ от крепости. Она продолжала существовать, но все больше и больше выступала не в качестве центрального качества города, а лишь как одна из форм системы обороны страны, которая в ряде случаев совпадала с городом, становясь в данном конкретном месте одной из его функций [6].

В центральной России это явление было окончательно изжито только при Павле I, разрешившем разбирать крепости в городах Московской губернии, где к 1790-м гг. они сохранялись в четырех поселениях: Дмитрове, Можайске, Коломне и Серпухове. Хотя их состояние «оставляло желало много лучшего», восстановление стен и башен одно время стояло в планах властей даже на исходе XVIII столетия [7]. Отказ от их поддержания говорил не только об ином понимания города, но и об изменения веса и места России на мировой арене.

Уже в последние годы XVIII в. города-крепости функционировали только на окраинах страны. Но, что показательно, они и тогда выступали в качестве уездных центров: Кронштадт [6], Моздок [6] и др.

Итогом реформы города Екатерины II стало утверждение за ним нового качества. Преобразования были направлены на развитие двух функций города, которые до сих пор остаются центральными при определении его характера: город как административный центр и город как хозяйственный центр. Третья черта городского поселения, признаваемая важнейшим признаком города - полифункциональность - по сути, является развитием его административных и хозяйственных качеств. Каждая из них сформировала свой набор типов городов. Хозяйственные функции города и типология требуют особого исследования и в данной работе специально не оценивались.

\section{Административная типология}

и установление служебной иерархичности городских поселений

В ходе административной и городской реформы Екатерины II определился набор городов и близких им городских поселений, формирующих городскую сеть Российской империи, просуществовавшую вплоть до ее гибели и принятия новых критериев и задач городского развития. Схема, на первый взгляд, несколько запутана. Впрочем, эта нелогичность существует только для нас, жителей другой исторической реальности, оценивающих город со своих позиций. Для россиян начала XIX столетия, проживавших внутри того исторического времени, она была естественна.

Для понимания структуры и характера сети городов и городских поселений, определившейся к началу XIX в., необходимо учесть несколько формирующих ее факторов, являющихся неотъемлемой частью того исторического времени. 
Первыци - административный характер города. При этом необходимо принять, что города не просто играли роль административного центра. Они, исполняя функцию территориального управления, находились фактически на государственной службе. Поселения разного уровня присутствовали (как и служащие в учреждениях) на разных ступенях своей «Табели о рангах». Обязанности разных уровней были определены. Как и у чиновников, у городов имелся свой набор статусных признаков. Не случайно присуждение в ходе реформ Екатерины II тому или иному поселению статуса города автоматически несло за собой набор непременных строений - порой излишних, но всегда подчеркивающих статус поселения как места пребывания власти, а также учреждение у города собственного герба. При этом, что характерно, посады, часто не уступавшие городам ни в качестве, ни в числе жителей, ни в характере и масштабе своей хозяйственной деятельности, гербов не имели. Причина этого в том, что они не имели отношения к административно-территориальной службе и вследствие этого не обладали правом на официальный статус города, а значит, и на наличие у себя герба.

Второй фактор - сословный характер городского населения. При получении статуса города все постоянное податное его население приписывалось к городским сословиям: купечеству, мещанству и цеховым, наделенным правами городского состояния. Кроме того, городские обыватели формировали городскую общину, которая имела право на органы городского самоуправления. Можно спорить о степени их эффективности и независимости от коронных властей (на практике присутствовали разные варианты таких взаимоотношений [8, с. 297-314]), но город обязан был иметь городское население и городское самоуправление. При этом поселение, назначенное городом, могло и не обладать достаточно активной хозяйственной жизнью, а его население носило статус городовых обывателей весьма формально.

Даже при утрате статуса уездного города и низведения поселения до посада бывшие городские жители (еще недавно крестьяне) сохраняли имя и права городовых обывателей, хотя и в урезанном виде [9].

Наличие обоих качеств (административный статус и городской характер населения) и составляли набор качественных признаков поселения, именуемого городом официально.

Что характерно, все города находились по отношению друг к другу в жесткой иерархии, которая порождала определенный набор внешних признаков и проявлений. В эту группу поселений входили города: столичные, до определенного времени центры генерал-губернаторств (наместничеств), города губернские и города уездные.

На начальном этапе, до проведения Екатериной II унификации городской сети, в ее составе присутствовали даже села, но только те, что играли роль центров своих уездов. Как, например, село Пертовка [10] (Пердом [11]), являвшееся центром Пошехонского уезда. Позже на его основе будет учрежден уездный город Пошехонье.

Весьма важно, что в процессе реформы Екатерины II все без исключения города (при весьма разной весовой категории) были городами уездными. Данное обстоятельство можно объяснить острой нехваткой при проведении административной реформы городских поселений. Это, бесспорно, так, но имеет значение и исторический фактор: в России на разных этапах ее многовековой истории город и приданная ему территория были нерасторжимо связаны. Город не существовал без своего уезда. Парадокс этот вызван, как мы полагаем, процессом колонизации страны. Согласно С.М. Каштанову, который проанализировал грамоты рязанских князей, понятие уезда как территориальной структуры, существующей «вокруг крупных городских центров», начало формироваться не позднее конца XIV в. [12, с. 105].

Таким образом, в качестве третьего фактора, определяющего особенность административной городской сети начала XIX в., выступает не только исполнение городом функций управления территорией, но непременное наличие у города собственного уезда. Это обстоятельство необходимо трактовать как развитие исторической традиции понимания характера города, укоренившегося за полутысячелетнюю историю страны, наличие нерасторжимой связи между городом и обустроенной им территории. Показательно, что при первоначальном плане Московской губернии уезд получил Звенигород, который сам был включен в состав другого Рузского уезда [13].

Развитие данного принципа породило парадоксальные для нашего понимания городские поселения - группу безуездных и заштатных городов. Лишенные основополагающего для городской административной сети качества - собственного уезда, - они не могли именоваться городами. Но власти или не стали лишать их жителей привилегированного статуса городских сословий, или, напротив, наделили жителей новоучрежденного города такими правами, но не дали их городу уезда. Это был своеобразный компромисс. В итоге поселения именовались городами, но к городам не относились. Поэтому, исходя из норм того времени, уместнее именовать их не городами, а городскими поселениями.

Четвертый важнейший фактор, без которого невозможно понять город и систему городских поселений страны в том виде, в каком они оформилась к началу XIX столетия, - это необходимость учитывать пограничный характер данного периода в истории русского города и наличие форм с разным характером и из разных исторических времен. Реформы Екатерины II ввели критерии города и упорядочили структуру городской сети, но они не уничтожили поселенческие формы, пришедшие из предшествующего времени и изживавшие себя. Старое и новое функционировало параллельно и взаимосвязанно. Одним из итогов этого было наличие близких (по сути, дублетных) структур (безуездный город и посад, посад и слобода, посад и местечко).

Многохарактерность поселений, относимых так или иначе к городским, еще более заметна на отдаленных территориях страны, где кроме русских присутствовали еще собственные территориальные и национальные формы (остроги, местечки, частные города, мызы [14]). Так, например, город Нарва имел свой уезд, но не входил в состав никакой губернии 
[15]. Впрочем, данный вопрос является предметом особого исследования.

Причины одновременного бытования старых и новых форм могут иметь несколько объяснений. Например, незавершенность процесса реформирования города, постепенное развитие которого наблюдается и далее. Консервативный подход при проведении реформирования, предусматривающий отказ от радикальных форм изменений городской сети и использование всех имеющихся в наличии структур.

Важной частью реформаторской деятельностью Екатерины II и ее сановников была осторожность, отказ от резких крутых поворотов и решений: «Действовать нужно не спеша, с осторожностью и с рассудком», - считала великая императрица [16, с. 87]. Новые формы не уничтожали старых, которые сохранялись и должны были со временем постепенно вытесниться нововведениями. Даже резкий в своих действиях Павел I, «закрывавший» многие «новоучрежденные» его матерью города, отказался от идеи перевести их в разряд посадов, а оставил городами, хотя и безуездными.

Одновременное бытование разных форм можно объяснить также неразвитостью городского строя России, недостаточной степенью устроения в нем основ капиталистического строя и буржуазного общества. Возможно, это и так. Но при анализе русского города и системы городов, оформившихся после реформ Екатерины II, необходимо оценивать не тезис его неразвитости, а в первую очередь выявление его характера, сформированного в условиях конкретного исторического времени и среды, обусловленного или порожденного этой средой. Тем более что капитализм для этого периода выступал лишь как один из укладов, и, проводя преобразования, правительство заботилось не о внедрении прогрессивной социально-экономической формы, а решало насущные задачи, исходя из понимания города, присущего тому времени, и используя имеющиеся в его распоряжении институты. При этом делало это максимально аккуратно, дабы, не создав ничего нового, одновременно не уничтожить имеющееся.

Кроме того, в поселенческой сети страны присутствовали неофициальные, но, говоря терминологией начала XX в., «фактические города». Причем необходимо отметить, что это явление признавалось уже современниками реформ Екатерины II и статистиками первой половины XIX в. Они хоть и именовали их по-разному (экономические села, купеческие слободы и даже «замечательные села» [17]), но имели в виду одно и то же: «людность» и торгово-ремесленный характер, а также нередко городскую среду и образ жизни. При этом, что весьма показательно, уже в последние десятилетия XVIII в. такие поселения в нарушение всех официальных норм нередко именовали ... городами, а следовательно, если и не считали их таковыми официально, то подразумевали как дань потенциалу.

Часто даже сановники в государственных документах без оглядки на правила писали городами поселения, не имеющие такового статуса, но соответствующие городскому облику. Как правило, это определялось. Так, в отчете главнокомандующего Москвы Я.А. Брюса о проведенной им инспекцион- ной поездке по Московской губернии, завершившейся 1 сентября 1785 г. [18], сановник дважды именует посад Троице-Сергиевого монастыря городом. А 3.Г. Чернышев адресует то же понятие московскому подгородному селу (!) Покровскому [19], которое являлось важнейшим центром ткацкого производства в губернии. Впрочем, это вопрос лежит в плоскости не административной, а экономической сети городов и городских поселений и требует особого рассмотрения.

Интересный пример трактовки обязательных признаков города дает жалоба жителей рязанского посада Скопин (позже одноименного города), отправленная в Сенат накануне созыва екатерининской Уложенной комиссии. Для заседания в нем местное купечество по примеру других городов избрало своего депутата, но Герольдмейстерская контора отказала ему в соответствующих полномочиях на основании того, что «Скопин не город, но волость, и состоит в ведомстве дворцовой конюшенной канцелярии». Купечество обжаловало данное решение в Сенате, приведя следующие аргументы городского статуса своего поселения: «Означенный город Скопин издревле написан был острожком, а не селом или какою слободою и по городовому обряду имел соборную и приходские церкви, также приписанный к селу уезд и несколько сел и деревень». Затем купцы указали, что их поселение имело воеводское управление, магистрат, и хотя в текущее время у власти в Скопине стоял лишь управитель, назначаемый из штабофицеров, «однако и до днесь оный Скопин в городовом списку значится городом и имеет до ныне земляной вал, по которому сделан был острог дубовый, по острогу обламы и башни и снабжен веленным снарядом и пушками, и ядрами с немалыми числом пороха и других принадлежностей...» [20, c. 27]. Таким образом, в своем «отношении» жители изложили практически весь набор признаков городского статуса, признаваемого в то время.

\section{Заключение}

В связи с вышесказанным выстраивается иерархическая цепочка городских типов, функционирующих в составе единой городской сети.

Первый. Официальные города. Штатные города города с полным набором признаков. К ним относятся: столичные города, города - центры наместничеств (столицы наместничества), уездные города, государственные села - центры уездов. Сверхштатные города - поселения, имеющие статус города, но лишенные главного его качества - собственного уезда: города-пригороды, безуездные города, заштатные города.

Второй. Поселения, которые не могут оцениваться или называться городами, но населены посадскими людьми с торгово-ремесленным характером деятельности: посады, местечки. Эти поселения в той системе призваны были вбирать в себя торговоремесленное население, начинавшее активное развитие сел и слобод, которые преобразовывались именно в посады, а не в города. Недооценка посадов и местечек (их территориального варианта) вызвана двумя причинами. Первая - наличие имевшегося критерия города - центра уезда. Вторая - напротив, отсутствие признания критерием города торгово-ремес- 
ленную деятельностью и «людность», т.е. того критерия, который не просто существует, а доминирует в наши дни.

Третий. Поселения, не являющиеся городами, но имеющие к ним отношения разного рода. Как правило, формальные: исторические города, городки и иные функциональные на тот момент типы (крепость, острог, заводские слободки и т.д.).

Четвертый. Фактически неофициальные города, признаваемые и называемые городами современниками. В их перечень можно отнести торговые села, торговые и «купеческие слободы» [22], которые не являлись даже посадами, но с течением времени могли быть преобразованы именно в них. Кроме того, бытовал и такой вариант, как «торговые подмонастырские села и слободы», которые часто подаются совместно в связи с их хозяйственным единством и функционированием. В документах середины XIX в. разные представители данной группы именуются и в более широком значении - «замечательные села».

\section{Список литературы:}

1. Екатерина Вторая. О величии России (избранные сочинения). М.: ЭКСМО, 2006. 829 с.

2. Юркина О.Г. Понятие «сибирская слобода» в отечественной историографии // Политология и политический процесс: сборник статей. Барнаул: Издательство Алтайского университета, 2004. С. 129-132.

3. Российский государственный архив древних актов (РГАДА). Ф. 10. Оп. І. Д. 243. С. 2.

4. ПСЗ-I. Т. XXVI. № 19963. С. 737.
5. ПСЗ-I. T. XXIII. № 17327. С. 694.

6. Расписание губернским и уездным штатным годам, по новому разделению губерний устроенным с показанием расстояния от обеих столиц и от губернского города. Отд. І. СПб., [1797-1800]. С. 11-13.

7. РГАДА. Ф. 16. Оп. 1. Д. 576. Л. 151.

8. Середа Н.В. Реформа управления Екатерины II: источниковедческое исследование: монография. М.: Памятники исторической мысли, 2004. 445 с.

9. ПСЗ-I. T. XXIV. № 18194. С. 763.

10. РГАДА. Ф. 16. ОП. 1. Д. 1012. Ч. 1. Л. 10 об.

11. ПСЗ-І. № 14635. С. 543.

12. Каштанов С.М. Из истории русского средневекового источника (Акты X-XVI вв.). М., 1996. $263 \mathrm{c}$

13. РГАДА. Ф. 16. Оп. 1. Д. 570. Л. 52 об.

14. ПСЗ-I. Т. XXII. № 15997. С. 150.

15. ПСЗ-I. XXIV. № 17827. С. 349.

16. Рахматуллин М.А. Императрица Екатерина Вторая // Наука и жизнь. 2003. № 4. С. 84-95.

17. Военно-статистическое обозрение Владимирской губернии // Военно-статистическое обозрение Российской империи. Т. VI. Ч. 2. СПб., 1852. С. 298.

18. РГАДА. Ф. 16. Оп. 1. Д. 576. Л. 150-152 об.

19. РГАДА. Ф. 16. Оп. 1. Д. 575. Ч. І. Л. 37-37 об.

20. Илизаров С.С. Становление иранистики в России. Из истории научной мысли XVIII столетия. М.: Янус-К, 2004. 188 с.

\section{OFFICIAL HIERARCHY AND CITY AND URBAN VILLAGE TYPOLOGY ESTABLISHED AT THE END OF XVIII-XIX CENTURIES}

(C) 2018

Belov Alexey Viktorovich, candidate of historical sciences, associate professor, senior researcher of History of Territory and Population of Russia Study Center Institute of Russian History of Russian Academy of Sciences (Moscow, Russian Federation)

Abstract. The article deals with one of the aspects of the cardinal reform of the city that took place in the reign of Catherine II. The reform of the city, taking place within the framework of the administrative and territorial reform of Catherine II, was closely related to the process of creating a network of new «small» provinces and the formation of a network of cities and urban settlements in each of the new entities administrative. The city network (a network of cities and urban settlements) was a complex (rather than a set) of settlements of a particular region, having (in the presentation of contemporaries) the status of the city or its official signs. In the course of its existence, a distribution of functions occurred within the network. The set of functions inherent in different urban settlements, determines their character and face in the broadest sense of the word. All functions can be conditionally divided into two groups: administrative and economic. In our study, attention was drawn to the approval of a set of administrative functions outside the city as part of the country's spatial and settlement to the establishment of certain types of cities and urban settlements, with a set of features and responsibilities. In this case, between the types of settlements a stable hierarchy as administrative centers established. The reason for its appearance is wider than the need for formal subjection. The network of cities and urban settlements of the country, established by the beginning of the XIX century, was complex with a heterogeneous structure. It included settlements, officially called cities according to the rules of its time, and other structures that do not belong to this group. The latter also performed city functions and were considered contemporaries on a par with the «official» cities, separating themselves from rural settlements. The name of settlements did not always correspond to their economic quality. Along with the administrative type of cities, there were intermediate forms of urban settlements, which, according to the norms of that time, did not apply to cities (non-resident cities, supernumerary cities, settlements, small towns). In addition, archaic forms of settlements connected with cities and partly fulfilling their functions, were preserved. An important peculiarity of this historical period is the simultaneous existence of numerous and diverse forms of urban settlements including archaic ones. This circumstance is caused by the transitional nature of the time, the implementation of administrative reform, as well as the desire of the authorities to implement the process of transformation without a radical breakdown and social protest.

Keywords: Russian city; pre-reform city; city reform; Catherine II; provincial reform; urban village; posad; settlement; out-of-town city; fortress; urbanization; city network; residential locations. 